\title{
Ribbon like appearance of the midsubstance fibres of the anterior cruciate ligament close to its femoral insertion site: a cadaveric study including 111 knees
}

\author{
Robert Śmigielski $\cdot$ Urszula Zdanowicz • \\ Michał Drwięga • Bogdan Ciszek • \\ Beata Ciszkowska-Łysoń $\cdot$ Rainer Siebold
}

Received: 1 August 2013/Accepted: 6 May 2014/Published online: 28 June 2014

(C) The Author(s) 2014. This article is published with open access at Springerlink.com

\begin{abstract}
Purpose Recently, the configuration of the anterior cruciate ligament (ACL) from its direct femoral insertion to midsubstance was found to be flat. This might have an important impact for anatomical ACL reconstruction. The purpose of this anatomical study was to evaluate the macroscopic appearance of the ACL from femoral to midsubstance.

Methods The ACL was dissected in 111 human fresh frozen cadaver knees from its femoral insertion to midsubstance, and the shape was described. The anatomical findings were documented on digital photographs and on
\end{abstract}

Electronic supplementary material The online version of this article (doi:10.1007/s00167-014-3146-7) contains supplementary material, which is available to authorized users.

R. Śmigielski ( $₫) \cdot$ U. Zdanowicz · M. Drwięga Orthopaedic and Sports Traumatology Department, Carolina

Medical Center, Pory 78, 02-757 Warsaw, Poland

e-mail: robert.smigielski@carolina.pl; rsmigielski@gmail.com

URL: http://www.carolina.pl

B. Ciszek

Department of Descriptive and Clinical Anatomy, Medical

University of Warsaw, Chalbinskiego 5, 02-004 Warsaw, Poland

B. Ciszkowska-Łysoń

Department of Radiology, Carolina Medical Center, Pory 78,

02-757 Warsaw, Poland

R. Siebold

Institute for Anatomy and Cell Biology, INF, Ruprecht-Karls University Heidelberg, Heidelberg, Germany

e-mail: rainer.siebold@atos.de

R. Siebold

HKF: Center for Spezialised Hip-Knee-Foot Surgery, ATOS Hospital Heidelberg, Bismarckstr. 9-15, 69115 Heidelberg, Germany video. Thirty knees were sent for computed tomography (CT), magnetic resonance imaging (MRI) and histology of the femoral ACL insertion.

Results Two millimetres from its direct femoral insertion, the ACL fibres formed a flat ribbon in all dissected knees without a clear separation between AM and PL bundles. The ribbon was in exact continuity of the posterior femoral cortex. The width of the ribbon was between 11.43 and $16.18 \mathrm{~mm}$ and the thickness of the ACL was only 2.54-3.38 mm. 3D CT, MRI and the histological examination confirmed above findings.

Conclusion This is a detailed anatomical study describing the ribbon-like structure of the ACL from its femoral insertion to midsubstance. A key point was to carefully remove the surface fibrous membrane of the ACL. A total of 2-3 $\mathrm{mm}$ from its bony femoral insertion, the ACL formed a flat ribbon without a clear separation between AM and PL bundles. The ribbon was in exact continuity of the posterior femoral cortex. The findings of a flat ligament may change the future approach to femoral ACL footprint and midsubstance ACL reconstruction and to graft selection.

Keywords Ribbon - Anterior cruciate ligament - ACL . Femoral insertion - Intraligamentous - Midsubstance · Anatomy

\section{Introduction}

A deep understanding of the morphology of the anterior cruciate ligament (ACL) is fundamental for its anatomical reconstruction, and most surgeons would agree that anatomical ACL reconstruction is the "restoration of the ACL to its native dimensions, collagen orientation and insertion sites" [18]. 
From previous anatomical studies, it is well known that the bony femoral ACL insertion is in the shape of a crescent, with the residents ridge (= lateral intercondylar ridge) as its straight anterior border and the posterior articular margin of the lateral femoral condyle as its convex posterior border $[3,5,6,9,10$, 13, 15, 19, 21, 23, 36, 39, 41, 43, 45, 52]. Most ACL fibres are aligned posterior to-and directly along the lateral intercondylar ridge. The longitudinal axis is in extension to the posterior femoral cortex and creates an angle to the femoral shaft axis which varies between $0^{\circ}$ and $70^{\circ}[6,14,25,41,42$, $43,45]$. The most posterior fibres of the femoral insertion are blending with the posterior cartilage of the lateral femoral condyle and with the periosteum of the posterior femoral shaft $[14,19,25,42,43,45]$. The femoral insertion site area shows big variations in size. According to the literature, the area varies between 46 and $230 \mathrm{~mm}^{2}$, the length between 12 and $20 \mathrm{~mm}$ and the width between 5 and $13 \mathrm{~mm} \mathrm{[6,10,14,} \mathrm{19,} \mathrm{21,}$ 24, 25, 29, 36, 42, 45]. Girgis (1975) [19] described the midsubstance of the ACL to be broad and flat with an average width of $11.1 \mathrm{~mm}$. Other authors reported the diameter in the range between 7 and $13 \mathrm{~mm}$ and the cross-sectional area to be "irregular", "oval", "corded" or "bundled" [2, 4, 6, 13, 19, 27-29, 36, 38, 51].

Recently, detailed observations of the femoral insertion site were reported by Mochizuki et al. [30], Iwahashi et al. [25] and Sasaki et al. [42]. Histologically, they described the ACL midsubstance fibres to form a narrow "direct" insertion posterior and along to the lateral intercondylar ridge which was continued by a fan-like "indirect" insertion towards the posterior femoral cartilage. Interestingly, they described the configuration of the ACL midsubstance to be "rather flat, looking like lasagna" [31].

The detailed understanding on the femoral insertion and the midsubstance shape of the ACL is very important for anatomical ACL reconstruction and may have a significant impact on clinical results.

The purpose of this anatomical cadaveric study was to evaluate the morphology of the ACL from its direct femoral insertion to midsubstance.

\section{Materials and methods}

One hundred and eleven fresh frozen cadaveric knees from 81 humans were used in this anatomical study: 45 male (of which 17 with both knees) and 36 female (of which 13 with both knees) from the MedCure tissue bank in Portland, Oregon, USA). Eleven knees with severe osteoarthritic changes (Grade IV according to the Outerbridge classification of osteochondral injuries [17]) were excluded from the study. Detailed demographic data are presented in Table 1.

Thighs and legs were sectioned approximately $30 \mathrm{~cm}$ away from the joint line. Knees were first thawed. All dissections were performed by the first author. All soft tissue superficial structures (anterior, posterior, medial and lateral side) to the level of the joint capsule were removed. The quadriceps tendon and patella with patellar tendon were excised distally at the level of the tibial tuberosity and also removed. After exposing the anterior aspect of the knee joint, the synovial tissue and Hoffa fat pad were carefully dissected and separated from the articular soft tissue structures (menisci and transverse ligament). Using an oscillating saw, the medial femoral condyle was cut through the intercondylar notch and was removed for better visualisation of the ACL and its femoral attachment. The key point in the dissections was the very careful and accurate removal of the synovial tissue surrounding the collagen fibres of the ACL.

After achieving good visualisation of the knee joint and ACL, anthropometric measurements of the ACL were taken $2 \mathrm{~mm}$ from its bony insertion and at midsubstance. Digital photographs and video recording were performed by a professional photographer using a Canon EOS 1 with a 24-70 mm lens. Measurements were made of the knee with the vertical tibia supported by the table and the femur manually fixed at full extension, as this is when the ACL achieves its maximum length (1). Measurements were performed under direct visualisation using vernier calipers (VIS, Poland).

Thirty knees were then sent for CT and MRI scans as well as histological examination of the femoral insertion site. CT scans were performed in eight different positions of the knee: from full extension and $20^{\circ}, 40^{\circ}, 60^{\circ}, 90^{\circ}$, $110^{\circ}, 130^{\circ}$ and $150^{\circ}$ of flexion and were made at $120 \mathrm{kV}$, $300 \mathrm{mAs}$, with $0.67 \mathrm{~mm}$ slice thickness; pitch 0.66 (Brilliance CT 40-channel). The knees were covered with plastic, put on their side on the CT table and adjusted to different degrees of flexion with a goniometer. Confirmation of exact knee position (flexion) was made on the basis

Table 1 Detailed demographic data of the study subjects

\begin{tabular}{lllllll}
\hline Sex & Side & Age & Height & BMI & Weight & Races \\
\hline 36 Female & 49 Right & Mean 67 y & Mean 1.70 m & Mean 22.6 & Mean 64.3 kg & 104 Caucasians \\
45 Male & 62 Left & $(32-74 \mathrm{y})$ & $(1.50-1.96 \mathrm{~m})$ & $(12.1-34.7)$ & $(36-116 \mathrm{~kg})$ & 6 African \\
& & & & & Americans \\
1 Indian American \\
\end{tabular}


of an overview (pilot) CT scan. The CT data-volume rendering (VR) and multi-planar reconstruction (MPR) were processed with Philips Brilliance CT applications (Philips, Netherlands).

Magnetic resonance imaging (MRI) examinations were performed in full extension (MR: 1.5, TSigna HDxt, GE Medical Systems machine, USA) using an 8 channel HD Knee Array in the following sequences: axial PD FSE TR/ TE 2600-2800/24-30 ms; matrix $512 \times 320$; slice thickness $1.1 \mathrm{~mm}$ Gap $0 \mathrm{~mm}$; Nex 5; sagittal PD FSE TR/TE 2800/24-30 ms; matrix $512 \times 320$; slice thickness $2 \mathrm{~mm}$ Gap $0 \mathrm{~mm}$; Nex 3; axial PD multi-planar reconstruction and processed with the Carestream Client.

The CT scans and the MRIs were performed to evaluate and reconfirm the macroscopic appearance of the midsubstance fibres of the ACL close to its femoral insertion. Histologies were performed using a light microscopy, H\&E stain and a $4 \times$-magnification to investigate the femoral ACL insertion including the proximal midsubstance fibres of the ACL close to its femoral insertion site.

The study was performed in the Department of Descriptive and Clinical Anatomy, in the Center for Biostructure Research, Medical University of Warsaw.

\section{Results}

In all dissected knees, the intraligamentous part of the ACL from close to its femoral insertion to midsubstance was observed to have a ribbon-like structure (Fig. 1a-c, Video 1). The femoral bony insertion of the ribbon was in exact continuity to the posterior femoral cortex (Fig. 2a, b). A clear separation into bundles was not possible. The morphometric measurements of the ACL were performed with calipers. The results for the width and thickness were as follow (Fig. 3a-c):

Mean width $2 \mathrm{~mm}$ from femoral insertion: $16.0 \mathrm{~mm}$ (range 12.7-18.1)

Mean thickness $2 \mathrm{~mm}$ from femoral insertion: $3.54 \mathrm{~mm}$ (range 2-4.8)

Mean cross-sectional area $2 \mathrm{~mm}$ from femoral insertion (calculated): $56.6 \mathrm{~mm}^{2}$

Mean width at midsubstance of ACL: $11.4 \mathrm{~mm}$ (range 9.8-13.8).

Mean thickness at midsubstance of ACL: $3.4 \mathrm{~mm}$ (range 1.8-3.9).

Mean cross-sectional area at midsubstance of ACL (calculated): $39.8 \mathrm{~mm}^{2}$

3D-CT reconstruction, MRI and histology reconfirmed the ribbon-like structure of the ACL. The collagen fibres were formed like a ribbon and approached to the femoral insertion in an acute angle creating a doubled tidemark at the bone (Fig. 4a, b).
This may be interpreted as a place within the whole attachment with either greater stress forces or microinjuries [7]. In both interpretations that would be the place where the greatest force is applied and therefore that would be the place where our graft should arise from ist tunnel.

\section{Discussion}

The most important finding of this study was that the ACL formed a flat ribbon-like ligament from its femoral insertion to midsubstance in all dissected knees. The ACL fibres were in exact continuity with the posterior femoral cortex and inserted just posterior to the intercondylar ridge. A clear separation into bundles was not possible. Anatomical observations were based on dissections of 111 cadaveric knees and were reconfirmed on CT, MRI and histologically.

Earlier reports from the literature are reconfirmed by our findings. In 2006, Mochizuki et al. [31] emphasised "thatafter removal of the surface membrane - the configuration of the intraligamentous part of the ACL was not oval" but rather flat, looking like "lasagna" $15.1 \mathrm{~mm}$ in length and $4.7 \mathrm{~mm}$ in width. Mochizuki et al. [31] also described the femoral insertion of the ACL to be very similar to the midsubstance configuration after the ligament surface membrane was removed from the attachment site. In 2010, Iwahashi et al. [25] reported on the "direct" femoral ACL insertion in which dense collagen fibres were connected to the bone by a fibrocartilaginous layer. This "direct" insertion was located in the depression between the lateral intercondylar ridge and 7-10 $\mathrm{mm}$ anterior to the articular cartilage margin. It measured $17.9 \mathrm{~mm}$ in length and $8.0 \mathrm{~mm}$ in width and covered an area of $128.3 \mathrm{~mm}^{2}$. These findings were reconfirmed by Sasaki et al. [42] who observed a narrow "direct" ACL insertion area posterior and along the lateral intercondylar ridge and a "lateral intercondylar posterior ridge". The lengths of the long and short axes of the insertion were 17.7 and $5.3 \mathrm{~mm}$, respectively. Another "indirect" ACL insertion was located just posterior to the direct insertion. The ACL from type I collagen blended into the posterior cartilage on immunohistological observations [42].

In a second report, Mochizuki et al. [30] just recently differentiated between the main attachment of the midsubstance ACL fibres and the attachment of the thin fibrous tissue. Later extended from the midsubstance fibres and broadly spread out like a fan on the posterior condyle. The authors termed these fibres "fan-like extension fibres" and described that these two different structures formed a fold at the border between the midsubstance fibres and the fanlike extension fibres in knee flexion.

MRI measurements were taken in 30 specimens, and reports from the literature also reconfirmed the flat ribbon- 

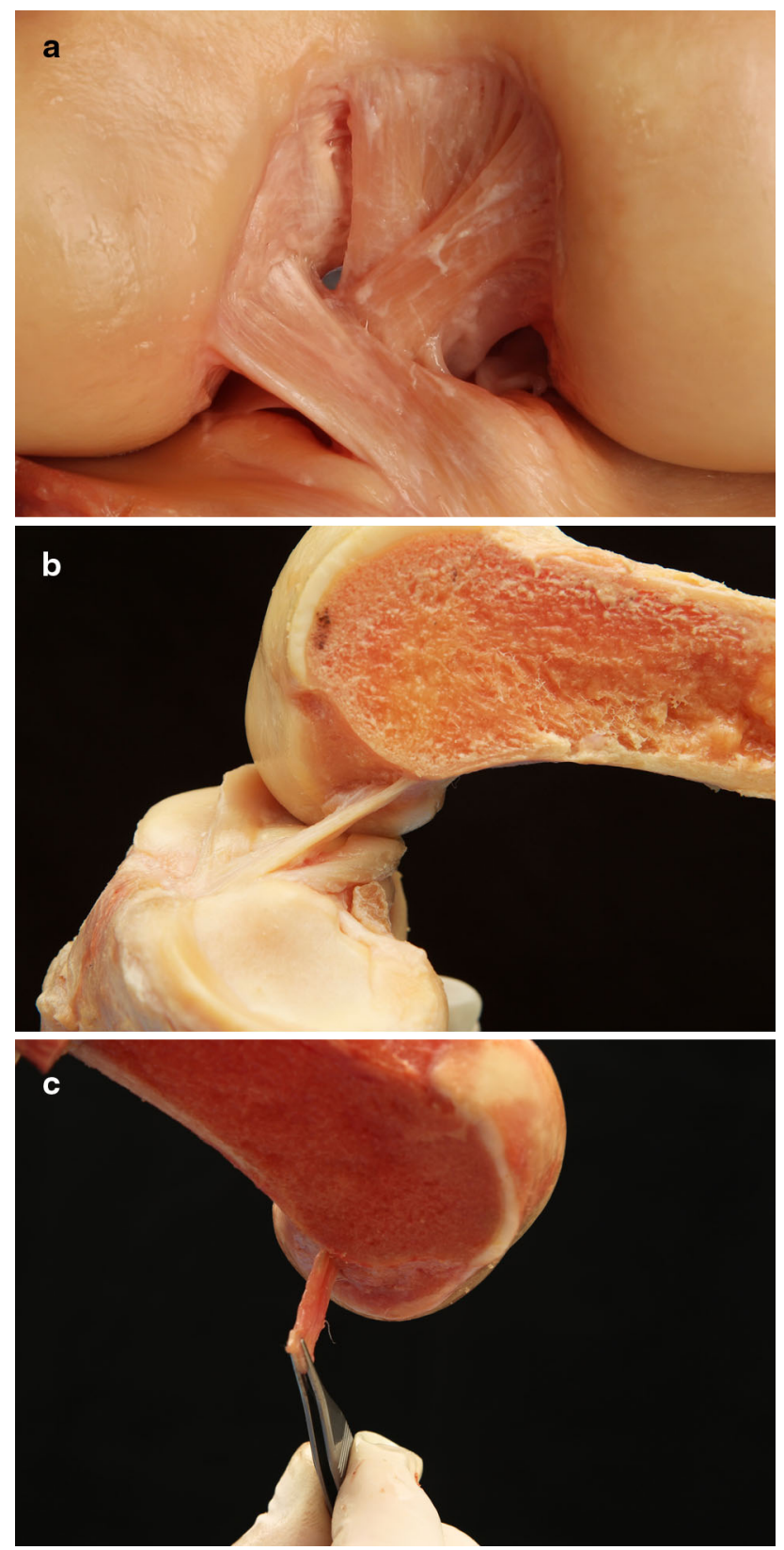

Fig. 1 a-c The ribbon shape of the ACL after careful removal of the synovial tissue: The ACL fibres form a flat ribbon $2 \mathrm{~mm}$ from its femoral attachment to midsubstance

like midsubstance ACL. Staeubli et al. [47] measured the midsubstance in 53 knees using a $0.23 \mathrm{~T}$ MRI and found a width of $6.1 \mathrm{~mm}$ in men and $5.2 \mathrm{~mm}$ in women, Muneta et al. [34] reported 5.5 and $5.1 \mathrm{~mm}$, respectively, and Pujol et al. [40] $6.1 \mathrm{~mm}$. Cohen et al. [9] scanned the knees of 50 patients using a $1.5 \mathrm{~T}$ MRI and measured the dimensions of the AM and PL bundles in the sagittal and coronal plane to be $5.1 \mathrm{~mm}$ by $4.2 \mathrm{~mm}$ (AM) and $4.4 \mathrm{~mm}$ by $3.7 \mathrm{~mm}$ (PL).

The cross-sectional area of the midsubstance ACL was calculated and measured 52 and $55 \mathrm{~mm}^{2}$ for woman and
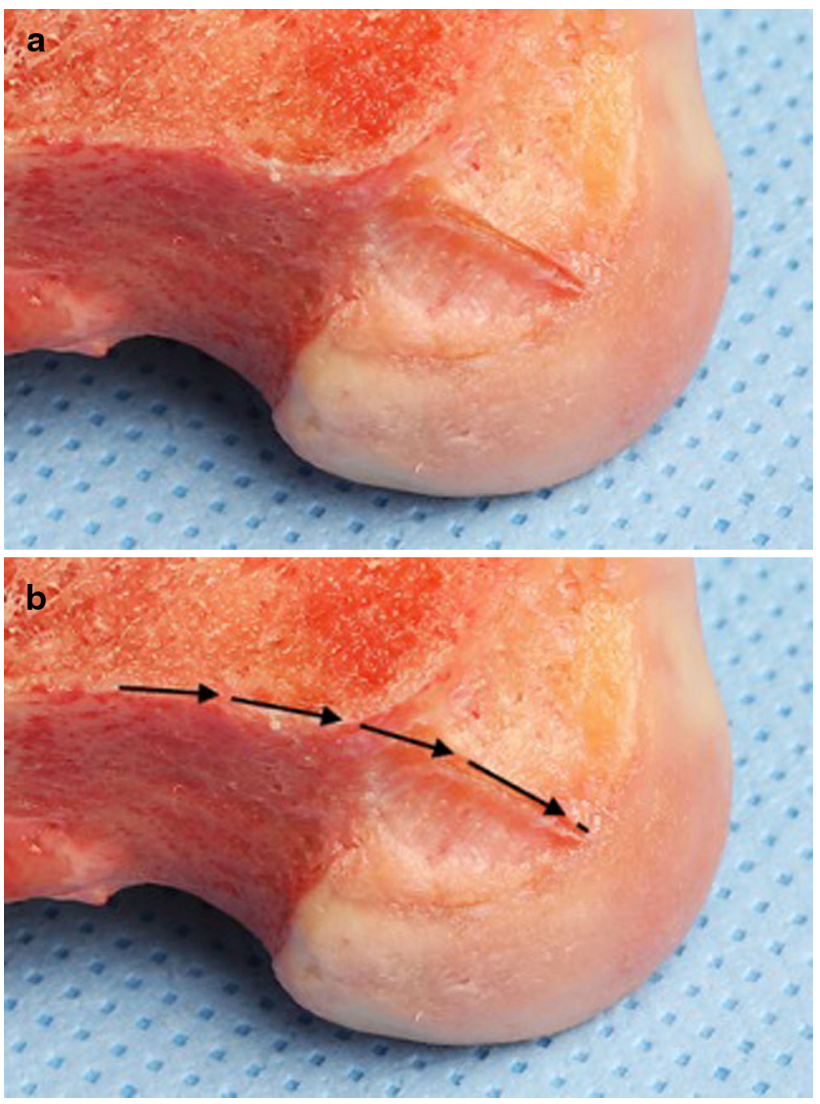

Fig. 2 a, b The direct insertion of the ribbon-like ACL fibres is in continuity of the posterior femoral cortex

men approximately $2 \mathrm{~mm}$ to its femoral insertion site and 33 and $38 \mathrm{~mm}^{2}$ at midsubstance, respectively. This is in agreement with several previous reports. Mochizuki et al. [31] approximated $65 \mathrm{~mm}^{2}$ as the femoral attachment area, Harner et al. [21] calculated approximately $40 \mathrm{~mm}^{2}$ at midsubstance, Hashemi et al. $46.8 \mathrm{~mm}^{2}$ [22] and Iriuchishima et al. $46.9 \mathrm{~mm}^{2}$ [24]. Differentiating between gender Anderson et al. [4] calculated a cross-sectional area of $44 \mathrm{~mm}^{2}$ for men and $36.1 \mathrm{~mm}^{2}$ for woman, Dienst et al. [12] of $56.8 \mathrm{~mm}^{2}$ for men and $40-50 \%$ less for women on MRI and Pujol et al. [40] of $29.2 \mathrm{~mm}^{2}$ (range $20.0-38.9 \mathrm{~mm}^{2}$ ).

Bundles could not clearly be separated from our dissections. This is in agreement with Welsh [49] and Arnoczky [5] and others reporting that the intraligamentous part of the ACL is a collection of individual fascicles that fan out over a broad-flattened area with no histological evidence for two separate bundles [5, 11, 13, 26, 36, 49]. However, the recent approach to the ACL is to differentiate between anteromedial and posterolateral bundle $[1,6,8,14,18-21,29,33,45,50]$ Some authors even described three separate ACL bundles [2, 35, 37]. The separation of the ACL into an AM and PL bundle was reconfirmed by Ferretti et al. [16], 

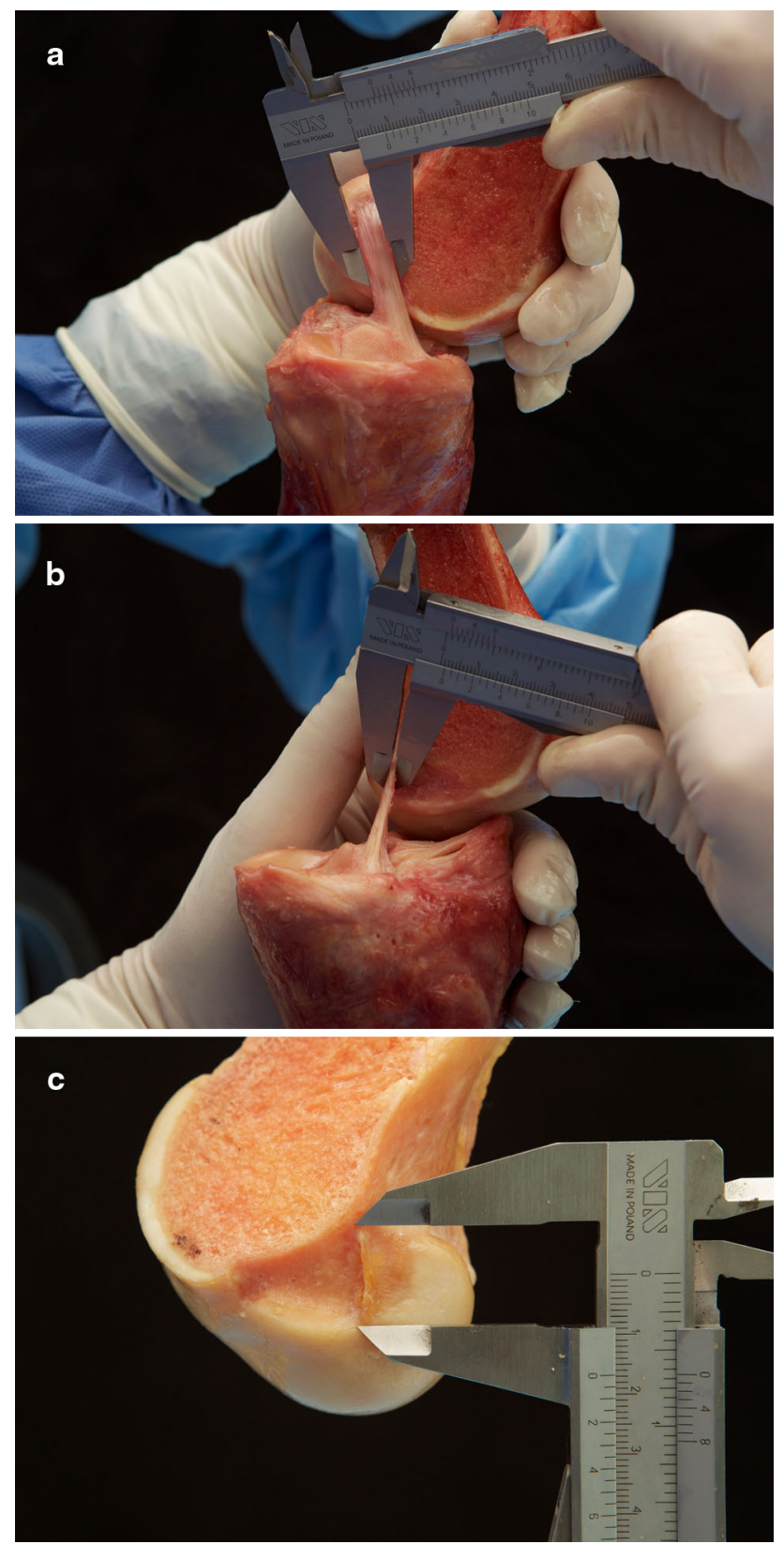

Fig. 3 a-c Measurement of the midsubstance width, thickness and long axis of the ACL using a calliper

which found a fine synovial septum in dissected ACLs of foetus.

In any case, the macroscopic anatomical separation of the ACL into two or three bundles remains very difficult and is controversial. According to Arnoczky et al. [5], the bundle anatomy oversimplifies somewhat as the ACL is actually a continuum of fascicles. In 1991, Amis and Dawkins [2] described that it was sometimes difficult to separate the ACL into three discrete bundles. In these cases, the anterior aspect of the ACL was folded itself in flexion suggesting an arrangement of bundles. It was still
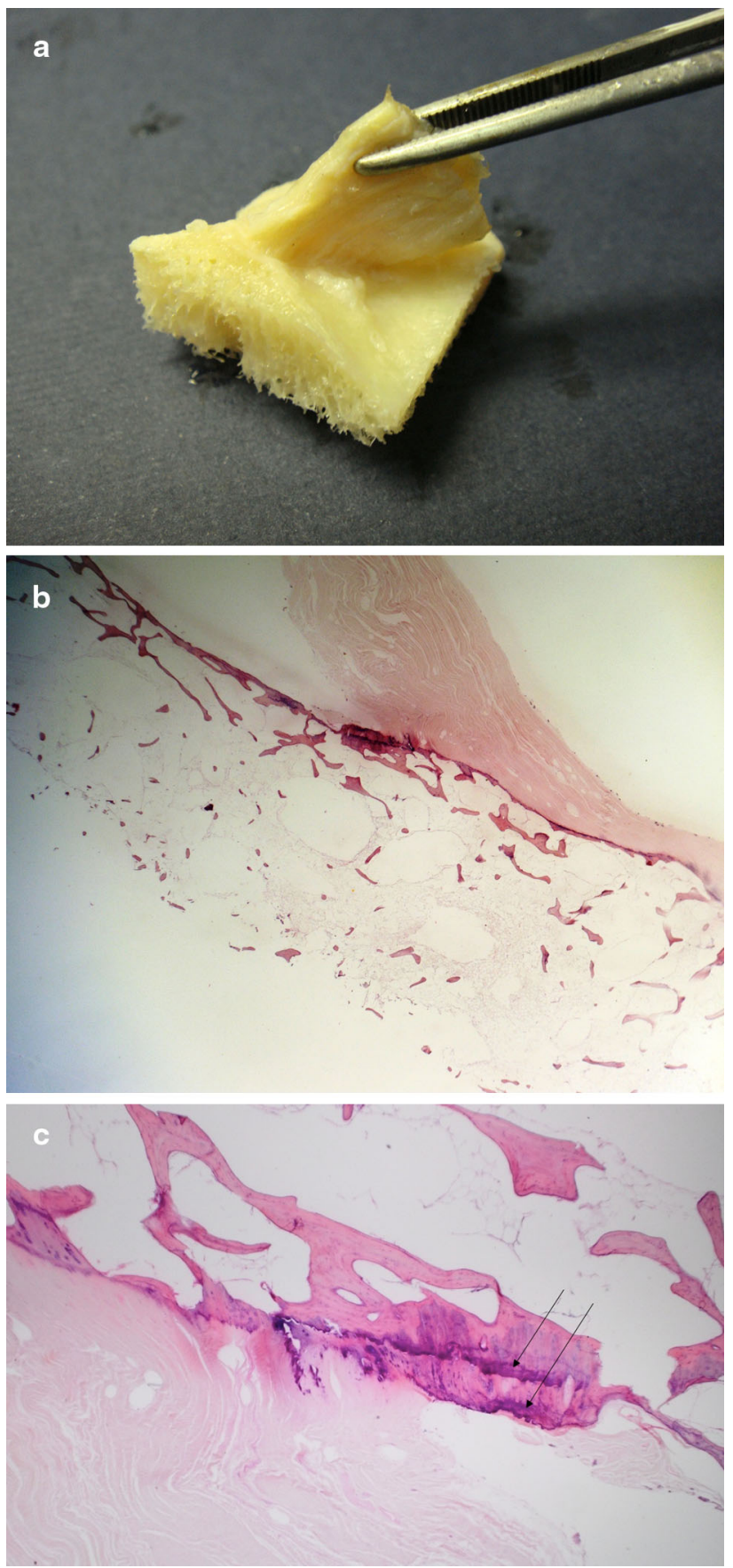

Fig. 4 a-b Histology of the direct femoral insertion of the ACL: macroscopic view (a) and microscopic view (b, c), (light microscopy, $\mathrm{H} \& \mathrm{E}$ stain, original magnification $\times 4$ ). b Note the sharp angle at which the fibres attach to the bone. Notice c double tidemarkmarked with arrows

possible to develop a three-bundle structure corresponding to the folding, but it felt that the teasing apart was artefactual. "In older specimens, however, the separate bundles were often obvious". Amis and Dawkins [2] concluded that the ACL wrinkles into the appearance of three bundles as the knee flexes. These bundles are often demonstrably 
separate structures, twisted together during flexion, but the use of the dissector to separate the fibre bundles can cross the threshold between demonstration of bundles and their creation.

From our observation, the "double bundle effect" was created by the twisted flat ribbon-like structure of the ACL from femoral to tibial, which lead to the impression of two or three separate bundles when the knee was flexed. This would reconfirm reports of Amis and Dawkins [2] who made similar observations.

The ribbon-like shape of the ACL and the flat but long femoral "direct" insertion site would support a rather flat anatomical footprint and midsubstance reconstruction. A double bundle ACL reconstruction using two 5-6 mm hamstring grafts $[25,31,32,42,44,46]$, a flat 5-6 mm patella tendon graft [43] or a flat 5-6 mm quadriceps tendon graft may be a better anatomical option than a large (and too wide) diameter graft for a single-bundle ACL reconstruction. Sasaki et al. [42] concluded that whereas the indirect insertion plays a role as a dynamic anchorage of soft tissue to bone allowing certain shear movements, the strength of anchoring is weaker than the direct insertion [48]. Therefore, it would be ideal to make the femoral tunnel on the direct insertion in the native ACL [42]. Mochizuki et al. [30] found that it is very difficult to reconstruct the fan-like indirect extension fibres by a bone tunnel; however, the midsubstance fibres of the ACL can be reconstructed. Of course, the most efficient anatomical and biomechanical ACL reconstruction has still to be proven in prospectively designed clinical long-term studies.

Our study was limited by the fact that all dissections were performed by the same investigator. Dissections have been done without magnification under direct visualisation, and the morphometric measurements were performed directly at the ligament using a calliper. However, the results of our macroscopic dissections are supported by radiological, histological findings and recent findings from the literature.

The clinical relevance of this study might have an impact on surgical technique used for anatomical ACL reconstruction.

\section{Conclusion}

This is a detailed anatomical study describing the ribbonlike structure of the ACL from its femoral insertion to midsubstance. A key point was to carefully remove the surface fibrous membrane of the ACL. Two millimetre from its bony direct femoral insertion the ACL formed a flat ribbon-like ligament without a clear separation between
AM and PL bundles. The ribbon was in exact continuity of the posterior femoral cortex. The findings of a flat ligament may change the approach to femoral ACL footprint and midsubstance ACL reconstruction and to graft selection.

Acknowledgments The authors gratefully acknowledge Piotr Zaorski, MD, Daniel Kopko, MD and Mateusz Janik, MD for active participation in cadaveric dissections; Maciej Pronicki, MD, PhD for providing histopathology examinations and Maciej Śmiarowski (maciej.smiarowski@gmail.com) for taking all photographs.

Open Access This article is distributed under the terms of the Creative Commons Attribution License which permits any use, distribution, and reproduction in any medium, provided the original author(s) and the source are credited.

\section{References}

1. Adachi N, Ochi M, Uchio Y, Iwasa J, Kuriwaka M, Ito Y (2004) Reconstruction of the anterior cruciate ligament. Single- versus double-bundle multistranded hamstring tendons. J Bone Joint Surg Br 86(4):515-520

2. Amis AA, Dawkins GP (1991) Functional anatomy of the anterior cruciate ligament. Fibre bundle actions related to ligament replacements and injuries. J Bone Joint Surg Br 73(2):260-267

3. Amis AA, Jakob RP (1998) Anterior cruciate ligament graft positioning, tensioning and twisting. Knee Surg Sports Traumatol Arthrosc 6(Suppl 1):S2-S12

4. Anderson AF, Dome DC, Gautam S, Awh MH, Rennirt GW (2001) Correlation of anthropometric measurements, strength, anterior cruciate ligament size, and intercondylar notch characteristics to sex differences in anterior cruciate ligament tear rates. Am J Sports Med 29(1):58-66

5. Arnoczky SP (1983) Anatomy of the anterior cruciate ligament. Clin Orthop Relat Res 172:19-25

6. Baer GS, Ferretti M, Fu FH (2008) Anatomy of the ACL. In: Fu FHCSB (ed) Current concepts in ACL reconstruction. SLACK, Thorofare, pp 21-32

7. Benjamin M, Toumi H, Ralphs JR, Bydder G, Best TM, Milz S (2006) Where tendons and ligaments meet bone: attachment sites ('entheses') in relation to exercise and/or mechanical load. J Anat 208(4):471-490

8. Buoncristiani AM, Tjoumakaris FP, Starman JS, Ferretti M, Fu FH (2006) Anatomic double-bundle anterior cruciate ligament reconstruction. Arthroscopy 22(9):1000-1006

9. Cohen SB, VanBeek C, Starman JS, Armfield D, Irrgang JJ, Fu FH (2009) MRI measurement of the 2 bundles of the normal anterior cruciate ligament. Orthopedics 32(9):70-75

10. Colombet P, Robinson J, Christel P, Franceschi JP, Djian P, Bellier G, Sbihi A (2006) Morphology of anterior cruciate ligament attachments for anatomic reconstruction: a cadaveric dissection and radiographic study. Arthroscopy 22(9):984-992

11. Dargel J, Pohl P, Tzikaras P, Koebke J (2006) Morphometric side-to-side differences in human cruciate ligament insertions. Surg Radiol Anat 28(4):398-402

12. Dienst M, Schneider G, Altmeyer K, Voelkering K, Georg T, Kramann B, Kohn D (2007) Correlation of intercondylar notch cross sections to the ACL size: a high resolution MR tomographic in vivo analysis. Arch Orthop Trauma Surg 127(4):253-260 
13. Duthon VB, Barea C, Abrassart S, Fasel JH, Fritschy D, Menetrey J (2006) Anatomy of the anterior cruciate ligament. Knee Surg Sports Traumatol Arthrosc 14(3):204-213

14. Edwards A, Bull AM, Amis AA (2008) The attachments of the anteromedial and posterolateral fibre bundles of the anterior cruciate ligament. Part 2: femoral attachment. Knee Surg Sports Traumatol Arthrosc 16(1):29-36

15. Ferretti M, Ekdahl M, Shen W, Fu FH (2007) Osseous landmarks of the femoral attachment of the anterior cruciate ligament: an anatomic study. Arthroscopy 23(11):1218-1225

16. Ferretti M, Levicoff EA, Macpherson TA, Moreland MS, Cohen M, Fu FH (2007) The fetal anterior cruciate ligament: an anatomic and histologic study. Arthroscopy 23(3):278-283

17. Fu FH, Bennett CH, Lattermann C, Ma CB (1999) Current trends in anterior cruciate ligament reconstruction. Part 1: biology and biomechanics of reconstruction. Am J Sports Med 27(6):821-830

18. Fu FH, Karlsson J (2010) A long journey to be anatomic. Knee Surg Sports Traumatol Arthrosc 18(9):1151-1153

19. Girgis FG, Marshall JL, Monajem A (1975) The cruciate ligaments of the knee joint. Anatomical, functional and experimental analysis. Clin Orthop Relat Res 106:216-231

20. Hamada M, Shino K, Horibe S, Mitsuoka T, Miyama T, Shiozaki Y, Mae T (2001) Single-versus bi-socket anterior cruciate ligament reconstruction using autogenous multiple-stranded hamstring tendons with endoButton femoral fixation: a prospective study. Arthroscopy 17(8):801-807

21. Harner CD, Baek GH, Vogrin TM, Carlin GJ, Kashiwaguchi S, Woo SL (1999) Quantitative analysis of human cruciate ligament insertions. Arthroscopy 15(7):741-749

22. Hashemi J, Mansouri H, Chandrashekar N, Slauterbeck JR, Hardy DM, Beynnon BD (2011) Age, sex, body anthropometry, and ACL size predict the structural properties of the human anterior cruciate ligament. J Orthop Res 29(7):993-1001

23. Hutchinson MR, Ash SA (2003) Resident's ridge: assessing the cortical thickness of the lateral wall and roof of the intercondylar notch. Arthroscopy 19(9):931-935

24. Iriuchishima T, Yorifuji H, Aizawa S, Tajika Y, Murakami T, Fu FH (2014) Evaluation of ACL mid-substance cross-sectional area for reconstructed autograft selection. Knee Surg Sports Traumatol Arthrosc 22(1):207-213

25. Iwahashi T, Shino K, Nakata K, Otsubo H, Suzuki T, Amano H, Nakamura N (2010) Direct anterior cruciate ligament insertion to the femur assessed by histology and 3-dimensional volume-rendered computed tomography. Arthroscopy 26(9 Suppl):S13-S20

26. Jacobsen K (1977) Osteoarthrosis following insufficiency of the cruciate ligaments in man. A clinical study. Acta Orthop Scand 48(5):520-526

27. Kennedy JC, Weinberg HW, Wilson AS (1974) The anatomy and function of the anterior cruciate ligament. As determined by clinical and morphological studies. J Bone Joint Surg Am 56(2):223-235

28. Kopf S, Musahl V, Tashman S, Szczodry M, Shen W, Fu FH (2009) A systematic review of the femoral origin and tibial insertion morphology of the ACL. Knee Surg Sports Traumatol Arthrosc 17(3):213-219

29. Luites JW, Wymenga AB, Blankevoort L, Kooloos JG (2007) Description of the attachment geometry of the anteromedial and posterolateral bundles of the ACL from arthroscopic perspective for anatomical tunnel placement. Knee Surg Sports Traumatol Arthrosc 15(12):1422-1431

30. Mochizuki T, Fujishiro H, Nimura A, Mahakkanukrauh P, Yasuda K, Muneta T, Akita K (2014) Anatomic and histologic analysis of the mid-substance and fan-like extension fibres of the anterior cruciate ligament during knee motion, with special reference to the femoral attachment. Knee Surg Sports Traumatol Arthrosc 22(2):336-344
31. Mochizuki T, Muneta T, Nagase T, Shirasawa S, Akita KI, Sekiya I (2006) Cadaveric knee observation study for describing anatomic femoral tunnel placement for two-bundle anterior cruciate ligament reconstruction. Arthroscopy 22(4):356-361

32. Mott HW (1983) Semitendinosus anatomic reconstruction for cruciate ligament insufficiency. Clin Orthop Relat Res 172:90-92

33. Muneta T, Sekiya I, Yagishita K, Ogiuchi T, Yamamoto H, Shinomiya K (1999) Two-bundle reconstruction of the anterior cruciate ligament using semitendinosus tendon with endobuttons: operative technique and preliminary results. Arthroscopy 15(6):618-624

34. Muneta T, Takakuda K, Yamamoto H (1997) Intercondylar notch width and its relation to the configuration and cross-sectional area of the anterior cruciate ligament. A cadaveric knee study. Am J Sports Med 25(1):69-72

35. Norwood LA, Cross MJ (1979) Anterior cruciate ligament: functional anatomy of its bundles in rotatory instabilities. Am J Sports Med 7(1):23-26

36. Odensten M, Gillquist J (1985) Functional anatomy of the anterior cruciate ligament and a rationale for reconstruction. $\mathrm{J}$ Bone Joint Surg Am 67(2):257-262

37. Otsubo H, Shino K, Suzuki D, Kamiya T, Suzuki T, Watanabe K, Fujimiya M, Iwahashi T, Yamashita T (2012) The arrangement and the attachment areas of three ACL bundles. Knee Surg Sports Traumatol Arthrosc 20(1):127-134

38. Papachristou G, Sourlas J, Magnissalis E, Plessas S, Papachristou K (2007) ACL reconstruction and the implication of its tibial attachment for stability of the joint: anthropometric and biomechanical study. Int Orthop 31(4):465-470

39. Petersen W, Tillmann B (2002) Anatomie und Funktion des vorderen Kreuzbandes. Orthopade 31(8):710-718

40. Pujol N, Queinnec S, Boisrenoult P, Maqdes A, Beaufils P (2013) Anatomy of the anterior cruciate ligament related to hamstring tendon grafts. A cadaveric study. Knee 20(6):511-514

41. Purnell ML, Larson AI, Clancy W (2008) Anterior cruciate ligament insertions on the tibia and femur and their relationships to critical bony landmarks using high-resolution volume-rendering computed tomography. Am J Sports Med 36(11):2083-2090

42. Sasaki N, Ishibashi Y, Tsuda E, Yamamoto Y, Maeda S, Mizukami H, Toh S, Yagihashi S, Tonosaki Y (2012) The femoral insertion of the anterior cruciate ligament: discrepancy between macroscopic and histological observations. Arthroscopy 28(8):1135-1146

43. Shino K, Suzuki T, Iwahashi T, Mae T, Nakamura N, Nakata K, Nakagawa S (2010) The resident's ridge as an arthroscopic landmark for anatomical femoral tunnel drilling in ACL reconstruction. Knee Surg Sports Traumatol Arthrosc 18(9):1164-1168

44. Siebold R (2011) The concept of complete footprint restoration with guidelines for single- and double-bundle ACL reconstruction. Knee Surg Sports Traumatol Arthrosc 19(5):699-706

45. Siebold R, Ellert T, Metz S, Metz J (2008) Femoral insertions of the anteromedial and posterolateral bundles of the anterior cruciate ligament: morphometry and arthroscopic orientation models for double-bundle bone tunnel placement - a cadaver study. Arthroscopy 24(5):585-592

46. Siebold R, Schuhmacher P (2012) Restoration of the tibial ACL footprint area and geometry using the modified insertion site table. Knee Surg Sports Traumatol Arthrosc 20(9):1845-1849

47. Staeubli HU, Adam O, Becker W, Burgkart R (1999) Anterior cruciate ligament and intercondylar notch in the coronal oblique plane: anatomy complemented by magnetic resonance imaging in cruciate ligament-intact knees. Arthroscopy 15(4):349-359

48. Weiler A, Hoffmann RF, Bail HJ, Rehm O, Sudkamp NP (2002) Tendon healing in a bone tunnel. Part II: histologic analysis after biodegradable interference fit fixation in a model of anterior cruciate ligament reconstruction in sheep. Arthroscopy 18(2):124-135 
49. Welsh RP (1980) Knee joint structure and function. Clin Orthop Relat Res 147:7-14

50. Yasuda K, Kondo E, Ichiyama H, Kitamura N, Tanabe Y, Tohyama H, Minami A (2004) Anatomic reconstruction of the anteromedial and posterolateral bundles of the anterior cruciate ligament using hamstring tendon grafts. Arthroscopy 20(10): $1015-1025$
51. Yasuda K, van Eck CF, Hoshino Y, Fu FH, Tashman S (2011) Anatomic single- and double-bundle anterior cruciate ligament reconstruction, part 1: basic science. Am J Sports Med 39(8):1789-1799

52. Zantop T, Petersen W, Fu FH (2005) Anatomy of the anterior cruciate ligament. Oper Tech Orthop 15(1):20-28 